ANO 10 • NÚMERO 19 • 2osem 2013 • ORGANICOM
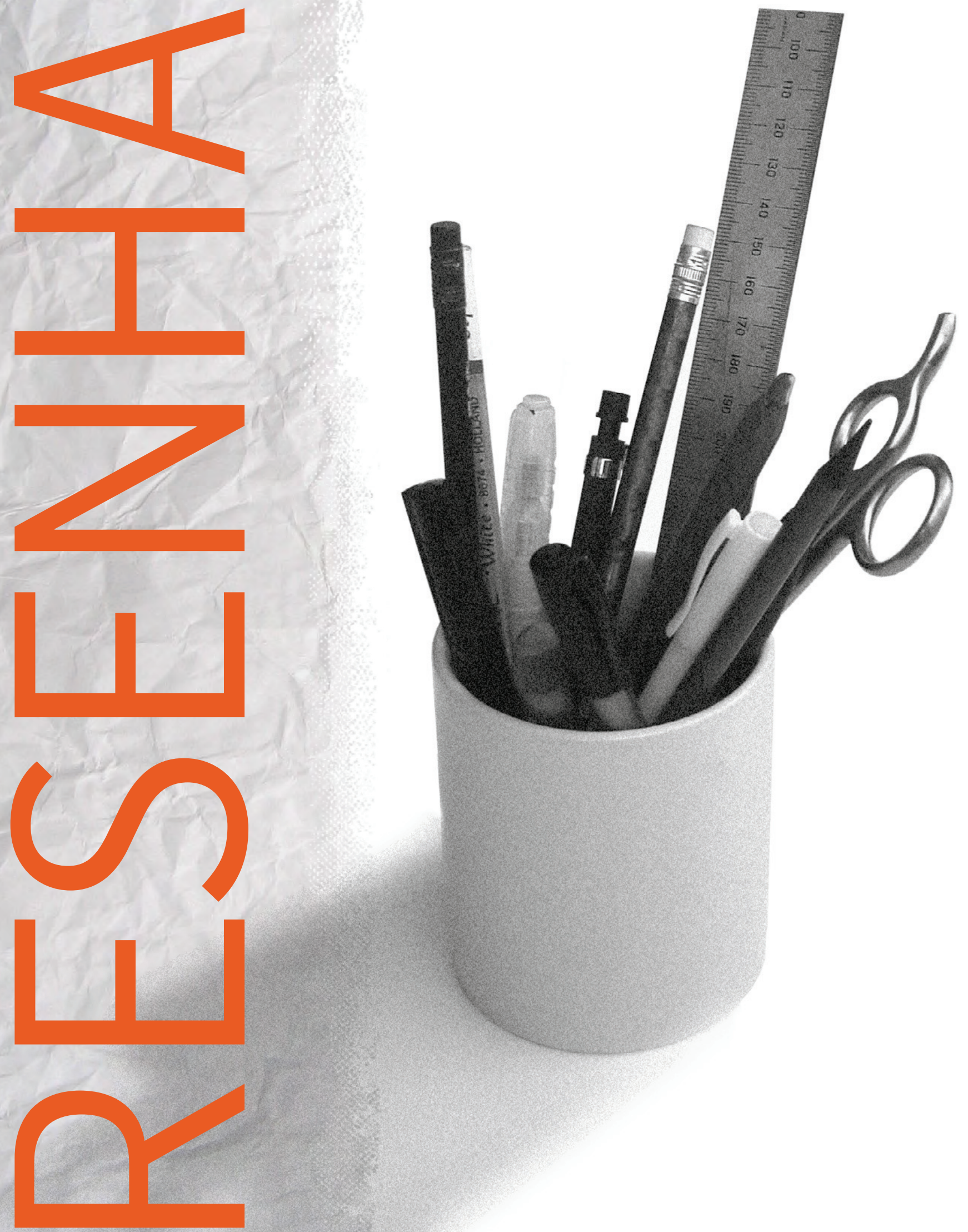


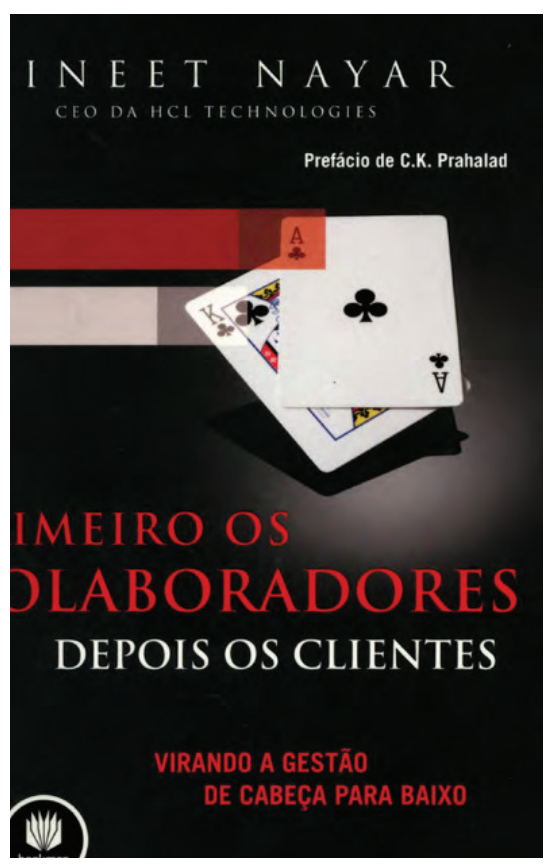

\section{Vineet Nayar}

Primeiro os colaboradores, depois os clientes: virando a gestão de cabeça para baixo

São Paulo

Bookman, 2012

$211 \mathrm{p}$.

Resenhado por

\section{Valéria Aparecida Cabral}

- Mestre em Ciências da Comunicação pela Escola de Comunicações e Artes da Universidade de São Paulo (ECA-USP)

- Graduada em Jornalismo e em Relações Públicas pela Faculdade Cásper Líbero

- Professora do Curso de Pós-Graduação Lato Sensu de Gestão Estratégica em Comunicação Organizacional e Relações Públicas (Gestcorp) da ECA-USP

- Membro do Conselho Superior do Instituto Federal de Educação, Ciência e Tecnologia de São Paulo

- Chefe da Universidade Corporativa do Metrô de São Paulo

- E-mail:vcabral@metrosp.com.br 


\section{O público interno como ponto de partida para a excelência na comunicação organizacional}

\section{The employees as the starting point for excellence in organizational communication}

\section{El público interno como punto de partida para una comunicación organizacional excelente}

vesso às estruturas hierárquicas tradicionais de organização do poder no trabalho, por entender que tais modelos já
não respondem com a eficácia necessária aos desafios empresariais contemporâneos, o engenheiro indiano Vineet
Nayar, CEO da HCL Technologies, discorre a importância da implementação da estratégia na obra Primeiro os
colaboradores, depois os clientes.

Não é de todo nova a teoria, pouco ortodoxa, que parte do pressuposto de que, em empresas de serviços, o valor agregado é criado na interface empregado-cliente e, portanto, faz sentido 'empoderar' os colaboradores que atuam na linha de frente, a fim de propiciar a entrega de serviços de valor singular, superando os ofertados pela concorrência.

Há mais de duas décadas, o empresário Ricardo Semler, CEO da Semco S. A., reconhecido por seus conceitos controvertidos de reengenharia corporativa, fez muito sucesso com a primeira edição do livro Virando a própria mesa (Ed. Best Seller, 1988), publicação que vem sendo relançada e continua fazendo sucesso, a qual já tratava sobre a questão do empowerment como caminho para o fortalecimento da democracia organizacional. Em Nuts! As soluções criativas da Southwest Airlines (Ed. Manole, 2000), a dupla Jackie e Kevin Freiberg apresenta a trajetória de Herb Kelleher, cofundador e presidente emérito da Southwest, companhia aérea norte-americana recordista na obtenção de resultados sucessivos e notavelmente superiores no negócio da aviação comercial, que enfatiza a importância de colocar o empregado em primeiro lugar como estratégia para 0 estabelecimento de uma organização de pessoas apaixonadas e compromissadas na conquista de resultados excepcionais. Outro exemplo vem de Hal Rosenbluth, empresário bem-sucedido, de destaque no setor do gerenciamento de viagens (Rosenbluth International), que narra a implementação, há mais de duas décadas, do seu programa de colocar 0 empregado em primeiro lugar, por meio da sua obra O cliente em $2^{\circ}$ segundo lugar (Ed. M. Books, 2011).

Apesar disso, o case narrado por Vineet, que nasceu em vilarejo no sopé do Himalaia, traz aspectos peculiares e interessantes de sua história de vida e descobertas e sobre como suas expectativas e ansiedades serviram de desafios 


\section{ANO 10 • NÚMERO $19 \cdot 2$ 2으 sem 2013 • ORGANICOM \\ O PÚBLICO INTERNO COMO PONTO DE PARTIDA

para a implementação de estratégias inovadoras junto aos colaboradores da HCLT. Essas estratégias são enfatizadas no prefácio do livro pelo consultor indiano-americanizado Coimbatore K. Prahalad, formado em Harvard e professor titular de estratégia corporativa da Universidade de Michigan, um dos autores do best-seller Competindo para o futuro: 1. 0 esforço deliberado em mexer na estrutura de poder; 2 . A busca contínua de democratização das informações e promoção do diálogo, como premissa para o estabelecimento de um ambiente de respeito e de confiança; 3. A preocupação com a construção de sentido e estabelecimento de consenso, dentro de uma atmosfera organizacional de descobertas e de viabilização de mudanças significativas.

Na obra, Vineet demonstra claramente sua preocupação com a comunicação interna, investindo tempo e energia (ou, como diz, "centenas de horas") para estabelecer canais de diálogo com as pessoas de toda a empresa. Nesse sentido, ele revisita, com a sua liderança, as estratégias e os instrumentos de comunicação; abre a "janela da informação"; estabelece novos espaços para questionamentos, troca e escuta; cria veículos específicos ou mesas para uma interlocução mais eficaz com os colaboradores; promove encontros e campanhas cheios de significado. Tudo isso por entender que "a comunicação de uma iniciativa é tão importante quanto a iniciativa em si" (p. 142). Mais: discorre sobre as reflexões e indagações feitas à sua equipe de profissionais de comunicação interna para uma abordagem mais significativa e relevante da comunicação sob a ótica do empregado e não como um espaço para "vender" internamente as iniciativas da organização.

Um livro interessante e oportuno. Uma boa leitura para os profissionais de comunicação que considerem a comunicação interna como o ponto de partida para a busca da excelência de todo o trabalho de relações públicas, visto que por meio desse público toda organização ou instituição estabelece sua identidade e se viabiliza. 